
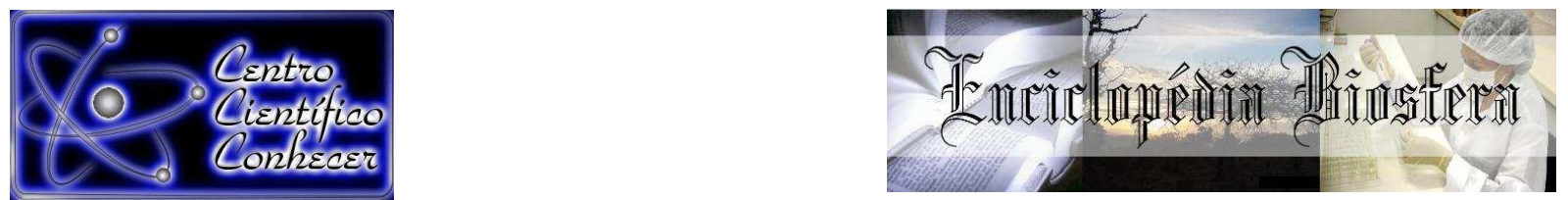

\title{
SUPERAÇÃO DE DORMÊNCIA TEGUMENTAR DE SEMENTES DA PATA DE VACA (Bauhinia forficata Link)
}

\footnotetext{
Helena Souza Ronchi ${ }^{2}$, Filipe Pereira Giardini Bonfim ${ }^{1}$, Isabela Cristina Gomes Honório $^{3}$, Raquel Popolo Silveira Capaz ${ }^{2}$, Isabela Borges Hernandes ${ }^{4}$

${ }^{1}$ Professor Assistente Doutor do Departamento de Horticultura, Faculdade de Ciências Agronômicas, UNESP Botucatu, São Paulo, Brasil.

${ }^{2}$ Mestranda do Programa de Pós Graduação em Agronomia: Horticultura, FCA, UNESP Botucatu, São Paulo, Brasil. E-mail: hsronchi@gmail.com

${ }^{3}$ Pós-Doutoranda em Agronomia: Horticultura, FCA, UNESP Botucatu, São Paulo, Brasil.

${ }^{4}$ Graduanda em Engenharia Florestal, FCA, UNESP Botucatu, São Paulo, Brasil.

Recebido em: 08/04/2016 - Aprovado em: 30/05/2016 - Publicado em: 20/06/2016 DOI: 10.18677/Enciclopedia_Biosfera_2016_114
}

\begin{abstract}
RESUMO
A espécie Bauhinia forficata Link. apresenta rápido crescimento e altas taxas de sobrevivência no campo, no entanto, suas sementes apresentam desuniformidades na germinação, sendo esta característica desfavorável para produção de mudas em viveiros florestais. Nesse sentido, objetivou-se identificar métodos para superar a dormência, promovendo a germinação e o vigor de sementes da espécie $B$. forficata Link. As sementes foram colhidas da área do Horto Medicinal, localizado no município de Botucatu, e submetidas aos seguintes tratamentos: imersão em água destilada $\left(25^{\circ} \mathrm{C}\right)$ por 24 horas, imersão em água destilada $\left(25^{\circ} \mathrm{C}\right)$ por 48 horas, imersão em ácido sulfúrico (PA) por 5 minutos, imersão em acido acético (PA) por 2 horas, imersão em água destilada aquecida $\left(65^{\circ} \mathrm{C}\right)$ por 2 horas, imersão em água gelada $\left(5^{\circ} \mathrm{C}\right)$ por 2 horas, testemunha (sem nenhum tipo de tratamento) e escarificação mecânica. As sementes foram avaliadas quanto à porcentagem de germinação, índice de velocidade de germinação, condutividade elétrica e comprimento radicular. Houve diferenças entre os tratamentos para todos os parâmetros avaliados. A imersão em água por 48 horas foi o que propiciou os melhores resultados quanto a porcentagem de germinação $97,75 \%$, índice de velocidade de germinação de 8,0 , condutividade elétrica $71,5 \mathrm{mS} \cdot \mathrm{cm}^{-1} \cdot \mathrm{g}^{-1} \mathrm{e}$ comprimento de raiz de $8,60 \mathrm{~cm}$.
\end{abstract}

PALAVRAS- CHAVE: espécies florestais, germinação, planta medicinal. 


\title{
DORMANCY OVERCOMING SEED TEGUMENTARY PATA DE VACA (Bauhinia forficata Link)
}

\begin{abstract}
The species Bauhinia forficata Link. presents fast growth and high survival rates in the country, however, its seeds have disuniformities germination, which is unfavorable characteristics for the production of seedlings in nurseries. Thus, this study aimed to identify methods to overcome dormancy, promote germination and seed vigor of the species B. forficata Link. Seeds were harvested from the area of the Medicinal Garden, located in Botucatu, and subjected to the following treatments: immersion in distilled water $\left(25^{\circ} \mathrm{C}\right)$ for 24 hours, soaking in distilled w ater $\left(25^{\circ} \mathrm{C}\right)$ for 48 hours, immersion sulfuric acid (PA) for 5 minutes immersion in acetic acid (PA) for 2 hours immersion in heated distilled water $\left(65^{\circ} \mathrm{C}\right)$ for 2 hours immersi on in cold water $\left(5^{\circ} \mathrm{C}\right)$ for 2 hours, control (without any treatment) and mechanical scarification. The seeds were evaluated for germination percentage, germination speed index, electrical conductivity and root length. There were differences between treatments for all parameters. Immersion in water for 48 hours was what led to the best results as the germination percentage $97.75 \%$, germination speed index of 8.0 , conductivity $71.5 \mathrm{mS} . \mathrm{cm}^{-1} \cdot \mathrm{g}^{-1}$ and root length $8.60 \mathrm{~cm}$.
\end{abstract}

KEYWORDS: forest species, germination, medicinal plant.

\section{INTRODUÇÃO}

Nas últimas décadas, houve aumento no interesse por plantas medicinais e seus respectivos produtos, resultando em novos mercados na área de fitoterápicos e plantas bioativas (ETHUR et al., 2011). Dentro das espécies arbóreas florestais, as espécies da família Fabaceae têm se mostrado com grande aptidão para fins medicinais.

O gênero Bauhinia tem sido frequentemente utilizado pela indústria farmacêutica para a produção de fitoterápicos, e umas das espécies mais utilizadas é a Bauhinia forficata Link (Fabaceae), por apresentar propriedades hipoglicemiantes comprovadas, assim como em tratamentos para inflamações renais (SANTOS \& RIEDER, 2013; LOPEZ \& SANTOS, 2015).

As sementes desse gênero apresentam dormência, do tipo tegumentar. Isto impede que ocorra o inicio do processo de germinação mesmo que em condições viáveis para que isso ocorra (ALVES et al., 2000). Sob enfoque evolutivo, a dormência é uma estratégia de sobrevivência, pois mantém a semente viável, retardando a germinação e a distribuindo no tempo (MENDOÇA et al., 2015). Porém, a desuniformidade na germinação não é uma característica favorável na produção de mudas em viveiros florestais, pois não oferece um padrão e dificulta a logística e o planejamento do plantio, além de aumentar custos da produção (MARTINS \& NAKAGAWA, 2008; SILVA et al., 2014).

A dormência tegumentar é uma barreira física causada pela casca da semente e para a produção de mudas dessa espécie é necessário superar essa dormência. As técnicas mais recomendadas para a superação desse tipo de dormência consistem em: imersão em ácido sulfúrico concentrado; a imersão em água e a escarificação mecânica 
(REBOUÇAS, 2012). Para as espécies B. monandra e $B$. ungulata, a técnica de imersão em ácido sulfúrico é considerada a mais eficiente para superação de dormência de sementes (ALVES et al., 2000). Nesse sentido, objetivou-se determinar o método mais eficiente para superação de dormência de sementes de $B$. forficata Link.

\section{MATERIAL E MÉTODOS}

As sementes de pata-de-vaca foram extraídas manualmente de frutos maduros oriundos de plantas presentes no Horto Medicinal, da Faculdade de Ciências Agronômicas, Unesp Botucatu (2250`36.38'S 4826`0 8“O). Foram coletadas as vagens que estavam abaixo da copa das árvores. As sementes foram retiradas das vagens e descartaram-se sementes chochas, imaturas, malformadas e danificadas. $O$ delineamento utilizado foi $o$ inteiramente casualizado com oito tratamentos e quatro repetições. Cada parcela experimental foi constituída por 50 sementes. Os tratamentos consistiram em: imersão em água destilada $\left(25^{\circ} \mathrm{C}\right)$ po r 24 horas: imersão em água destilada $\left(25^{\circ} \mathrm{C}\right)$ por 48 horas; imersão em ácido sul fúrico (PA) por 5 minutos; imersão em acido acético (PA) por 2 horas; imersão em água destilada aquecida (65ㄷ) por 2 horas; imersão em água gelada $\left(5^{\circ} \mathrm{C}\right)$ por 2 horas; testemunha (sem nenhum tipo de tratamento); escarificação mecânica (corte na extremidade oposta ao eixo embrionário da semente).

Os testes para avaliação do potencial fisiológico (germinação e vigor) foram realizados em rolo de papel umedecido com água destilada na proporção de duas e meia vezes à massa do papel e colocado para germinar sob a temperatura de $25^{\circ} \mathrm{C}$ e fotoperíodo de 16 horas de luz e 8 horas de escuro, em câmara do tipo BOD.

As sementes foram avaliadas quanto à porcentagem de germinação (PG): obtida aos 28 dias após a semeadura, por meio do número de plântulas normais, expressos em porcentagem; o índice de velocidade de germinação (IVG): realizado de acordo com metodologia proposta por MAGUIRE (1962); comprimento da raiz (CR): medido por meio da distância entre a o ápice e a base das raízes, e os resultados expressos em milímetros $(\mathrm{mm})$ e condutividade elétrica (CE): avaliada por meio da medição da CE da solução de embebição das sementes, juntamente com os tratamentos empregando quatro repetições de 50 sementes por tratamento, cuja massa das sementes foi determinada e as mesmas inseridas em recipiente contendo $75 \mathrm{ml}$ de água destilada. (MARTINS \& NAKAGAWA, 2008). A embebição foi realizada a $25^{\circ} \mathrm{C}$ por 24h; e, decorrido esse período, a condutividade elétrica da solução foi determinada por meio de condutivímetro, e os valores, expressos em $\mathrm{mS} \mathrm{cm}^{-1} \mathrm{~g}^{-1}$ de sementes (MARTINS \& NAKAGAWA, 2008).

A significância do efeito de tratamentos foi determinada por meio do Teste $F$, sendo as médias comparadas por meio do Teste de Tukey $(p<0,05)$.

\section{RESULTADOS E DISCUSSÃO}

Os métodos de superação de dormência ocasionaram diferentes respostas nos atributos fisiológicos de sementes de $B$. forficata (Tabela 1). 
TABELA 1: Porcentagem de germinação (PG.); índice de velocidade de germinação (IVG); condutividade elétrica (CE) e comprimento da raiz (CR) de plântulas oriundas de sementes submetidas a diferentes métodos de superação de dormência em sementes de pata-de-vaca (Bauhinia forficata Link.).

\begin{tabular}{|c|c|c|c|c|}
\hline TRATAMENTOS & PG (\%) & IVG & CE $\left(\mathrm{mS} \mathrm{cm}^{-1} \mathrm{~g}^{-1}\right)$ & CR (cm) \\
\hline $\begin{array}{c}\text { Imersão em água } \\
\text { destilada }\left(25^{\circ}\right) \text { por } \\
24 \text { horas }\end{array}$ & $85 a b$ & $6,58 \mathrm{a}$ & $75,25 d$ & $7,32 a b$ \\
\hline $\begin{array}{c}\text { Imersão em água } \\
\text { destilada (25๔) por } \\
48 \text { horas }\end{array}$ & $97,75 a$ & $8,02 \mathrm{a}$ & $71,50 \mathrm{~d}$ & $8,60 \mathrm{a}$ \\
\hline $\begin{array}{l}\text { Imersão em ácido } \\
\text { sulfúrico por } 5 \\
\text { minutos }\end{array}$ & $43,75 c$ & 3,82 b & $117,50 \mathrm{a}$ & $2,60 \mathrm{c}$ \\
\hline $\begin{array}{l}\text { Imersão em acido } \\
\text { acético por } 2 \text { horas }\end{array}$ & $42,50 c$ & $3,50 \mathrm{~b}$ & $95,25 \mathrm{c}$ & $3,22 \mathrm{c}$ \\
\hline $\begin{array}{l}\text { Imersão em água } \\
\text { destilada aquecida } \\
\left(65^{\circ} \mathrm{c}\right) \text { por } 2 \text { horas }\end{array}$ & $37,25 c$ & $2,825 b$ & $99,50 \mathrm{bc}$ & $2,75 \mathrm{c}$ \\
\hline $\begin{array}{c}\text { Imersão em água } \\
\text { gelada }\left(5^{\circ} \mathrm{c}\right) \text { por } 2 \\
\text { horas }\end{array}$ & $42,50 \mathrm{c}$ & $2,55 \mathrm{~b}$ & $72,25 d$ & $3,22 \mathrm{c}$ \\
\hline $\begin{array}{l}\text { Escarificação } \\
\text { mecânica }\end{array}$ & $82 a b$ & $8,07 \mathrm{a}$ & $107,50 a b$ & $7,15 a b$ \\
\hline $\begin{array}{l}\text { Testemunha (sem } \\
\text { nenhum tipo de } \\
\text { tratamento) }\end{array}$ & $62,50 \mathrm{bc}$ & $3,90 \mathrm{~b}$ & $70,25 \mathrm{~d}$ & $3,72 \mathrm{bc}$ \\
\hline CV (\%) & 18,80 & 17,61 & 5,13 & 33,56 \\
\hline
\end{tabular}

- As médias seguidas pela mesma letra na coluna não diferem entre si pelo teste de Tukey a $5 \%$ de probabilidade.

A imersão em água destilada por 48 horas foi efetiva na superação da dormência (Tabela 1). Isso porque as análises avaliadas expressaram as maiores taxas de germinação, velocidade de germinação e crescimento da plântula, mostrando boa qualidade fisiológica das sementes submetidas nesse tratamento. Sementes com altas taxas de velocidade de germinação são mais vigorosas e tendem alcançar maiores taxas de germinação (SHIMIZU et al., 2011). Esta é característica desejável na produção de mudas, pois, elas ficam menos tempo suscetíveis a condições climáticas adversas (MARTINS et al., 1999).

Para as espécies B. monandra e B. ungulata, ALVES et al. (2000) observaram que, para a porcentagem de germinação (PG) e índice de velocidade de germinação (IVG), o tratamento com ácido sulfúrico concentrado foi o que apresentou melhor resultado para as mesmas variáveis analisadas, dados esses que diferem do presente estudo. Já para a espécie $B$. divaricata $L$., verificou-se que as maiores porcentagens de germinação foram observadas no tratamento de escarificação mecânica (ALVES et al., 
2004), o que mostra que não há padrão nas técnicas de superação de dormência para as espécies do gênero Bauhinia. Portanto, isto indica a importância dos estudos específicos para cada espécie na contribuição de apontar qual a técnica mais eficiente.

A condutividade elétrica tem sido proposta de parâmetro a ser avaliado nos testes de qualidade fisiológica das sementes. O valor da condutividade é função da quantidade de lixiviados na solução e está diretamente relacionada com a integridade das membranas celulares (CARVALHO \& VIEIRA, 1994). Dessa maneira, quanto maior a condutividade elétrica, maior é a lixiviação de solutos, indicando a perda da integridade das membranas celulares e o baixo vigor da semente (POPINIGIS, 1985).

O tratamento com de imersão em ácido sulfúrico por 5 minutos proporcionou o maior valor de condutividade de elétrica, apontando que esse tratamento afetou significativamente a integridade das membranas, danificando-as, comprometendo diretamente a qualidade fisiológica da semente e o desenvolvimento da plântula como observado na Tabela 1, as menores taxas para a porcentagem de germinação e desenvolvimento da plântula. 10 minutos com ácido sulfúrico também propiciou os menores resultados para o crescimento da plântula

\section{CONCLUSÃO}

A técnica indicada para a superação de dormência da espécie Bauhinia forficata Link. é a de imersão em água destilada por 48 horas. Essa técnica é simples, de menor custo e oferece menores riscos à segurança de pessoas que venham a trabalhar com a produção de mudas da espécie em estudo.

\section{AGRADECIMENTOS}

À CAPES pelo auxílio financeiro para esse trabalho.

\section{REFERÊNCIAS}

ALVES, A. U.; DORNELAS, C. S. M.; BRUNO, R. DE L. A.; ANDRADE, L. A. DE; ALVES, E. U. Superação da dormência em sementes de Bauhinia divaricata L. Revista Acta Botânica Brasilica, v. 18, n. 4, p.871-879, 2004.

ALVES, M. M.; ALVES, E.U.; SILVA-MOURA, S. dos S.; ARAUJO, L. R. de; SILVA,R. dos SANTOS; URSULINO, M. M. Emergência e crescimento inicial de plântulas de Platymiscium floribundum Vog. em função de diferentes posições e profundidades de semeadura. Ciência Rural, v. 44, n. 12, p.2129-2135, 2014.

ALVES, M. da C. S.; MEDEIROS-FILHO, S.; ANDRADE-NETO, M.; TEÓFILO, E. M. Superação da dormência em sementes de Bauhinia monandra Britt. E Bauhinia ungulata L. - Caesalpinoideae 1. Revista Brasileira de Sementes, v. 22, n. 2, p.139$144,2000$.

AZEVEDO, S. K. S. de; SILVA, I. M. Plantas medicinais e de uso religioso comercializadas em mercados e feiras livres no Rio de Janeiro, RJ, Brasil. Revista Acta Botânica Brasilica, v. 20, n. 1, p.185-194, 2006. 
BRASILIA., OLIVVEIRA, M. C. de O. Embrapa Cerrado. Manual de viveiro e Produção de Mudas: Espécies arbóreas nativas do Cerrado. Asa Norte: Rede de Sementes do Cerrado, 2016. 124 p.

COLOMBO. FOWLER, J. A. P. Embrapa Florestas. Dormência em sementes florestais. Colombo: Embrapa Florestas, 2000. 27 p.

COLOMBO. CARVALHO, P. E. R. Embrapa Florestas. Circular Técnica - Pata de vaca. Colombo: Embrapa Florestas, 2003. 12 p.

DAVIDE, A. C.; SILVA, E. A. A. da. Produção de sementes e mudas de espécies florestais: Ufla, 2008. $175 \mathrm{p}$.

ETHUR, L. Z. JOBIM, J.C.; RITTER, J.G.; OLIVEIRA, G.; TRINDADE, B.S. Comércio formal e perfil de consumidores de plantas medicinais e fitoterápicos no município de Itaqui - RS. Revista Brasileira de Plantas Medicinais, v. 13, n. 2, p.121-128, 2011.

LOPES, J.L.W.; GUERRINI, I.A. SAAD, J.C.C.; SILVA, M.R. Atributos químicos e físicos de dois substratos para a produção de mudas de eucalipto. Revista Cerne, Lavras, v.14, n.4, p. 358-367, 2006.

LÓPEZ, R. E. da S.; SANTOS, B. C. dos. Farmacologia: Bauhinia forficata Link (Fabaceae) . Revista Fitos, v. 3, n. 9, p.161-252, 2015. DOI 10.5935/24464775.20150018

LORENZI, H. Árvores brasileiras: manual de identificação e cultivo de plantas arbóreas nativas do Brasil. Nova Odessa: Plantarum, 2002. 368 p.

MAGUIRE, J. Speed of germination-aid in selection and evaluation for seedling emergence and vigor. Crop Science, v.2, n.1, p. 176-177, 1962.

MARTINS, C. C.; NAKAGAWA, J.; BOVI, M. L. A. Efeito da posição da semente no substrato e no crescimento inicial das plântulas de palmito-vermelho (Euterpe espiritosantensis Fernandes - PALMAE). Revista Brasileira de Sementes, v. 21, n. 1, p.164-173, 1999

MARTINS, C. C.; NAKAGAWA, J. Germinação de sementes de Stryphnodendron adstringens (Mart.) Coville de diferentes origens submetidas a tratamentos para superação de dormência. Revista Árvore, v. 32, n. 6, p.1059-1067, 2008.

MENDONÇA,G. S; MARTINS,C. C.; MARTINS, D.; LOPES, M. T. G. Aspectos físicos e fisiológicos de sementes de Fimbristylis dicothoma relacionados à germinação e dormência1. Revista Ciência Agronômica, v. 46, n. 3, p.539-545, 2015. 
POPINIGIS, F. Fisiologia da Semente. 2. ed. Brasilia: Agiplan, 1985. 289 p. Disponível em: <http://www.popinigis.net/Home/Fisiologia>. Acesso em: 5 mar. 2016.

REBOUÇAS, A. C. M. N.; MATOS, V. P.; FERREIRA, R. L. C.; SENA, L. H. de M.; SALES, A. G. de F. A.; FERREIRA, E. G. B. de S. Métodos para superação da dormência de sementes de quixabeira (Sideroxylon obtusifolium (Roem. \& Schult.) T.D.Penn.). Ciência Florestal, v. 22, n. 1, p.183-192, 2012.

ROSA, S. G. T. da; FERREIRA, A. G. Germinação de sementes de plantas medicinais lenhosas. Revista Acta Botânica Brasilica, v. 15, n. 2, p.147-154, 2001.

SHIMIZU, E. S. C.; PINHEIRO, H. A.; COSTA, M. A.; SANTOS FILHO, B. G. dos Aspectos fisiológicos da germinação e da qualidade de plântulas de Schizolobium amazonicum em resposta à escarificação das sementes em lixa e água quente. Revista Árvore, v. 35, n. 4, p.791-800, 2011.

SILVA, R. C da; VIEIRA, E. S. N.; PANOBIANCO, M. Técnicas para superação da dormência de sementes de guanandi. Pesquisa Agropecuária Brasileira, v. 49, n. 9, p.719-727, 2014. 